\title{
Muscle Activity Ratios of Scapular Stabilizers During Closed Kinetic Chain Exercises in Healthy Shoulders: A Systematic Review
}

\author{
Damla Karabay, Yusuf Emük, and Derya Özer Kaya
}

\begin{abstract}
Context: Selective strengthening of scapular stabilizers is one of the emphases of the recent literature. Closed kinetic chain (CKC) exercises are used extensively in shoulder rehabilitation. However, a limited number of studies have reported scapular muscle ratios during CKC exercises. Objectives: To determine the CKC exercises producing the optimal ratios of the scapular stabilizer muscles in healthy shoulders. Evidence Acquisition: A systematic search within PubMed, Embase, CINAHL Plus, and SPORTDiscus with Full Text and ULAKBIM National Medical Database was performed up to January 2018. Studies were selected according to the predetermined criteria. If the pooled mean ratios (upper trapezius [UT]/middle trapezius [MT], UT/lower trapezius [LT], and UT/serratus anterior [SA]), which were calculated from the percentage of maximum voluntary contractions of muscles, were $<0.60$, these exercises were considered as ideal for higher activation of the MT, LT, and SA than the UT. Evidence Synthesis: The search identified 1284 studies, and 29 observational studies were included for review. Seventy-nine CKC exercises were determined. Four exercises for the MT, 9 for the LT, and 59 for the SA were identified from the articles as being optimal exercises to activate the specified muscle more than the UT. Conclusions: This review identified optimal CKC exercises that provide good ratios between the MT, LT, and SA with the UT. Most exercises have optimal UT/SA ratios, but some exercises performed on unstable surfaces may lead to excessive activation of the UT relative to the SA. For the UT/MT, the isometric low row, inferior glide, and half supine pull-up with slings are the ideal exercises. Isometric one-hand knee push-up variations seem to be the best choice for the UT/LT. The results suggest that many CKC exercises may be utilized to enhance scapular muscle balance when rehabilitating shoulder pathology.
\end{abstract}

Keywords: electromyography, exercise therapy, subacromial impingement syndrome

\section{Context}

During movements of the shoulder, the scapula moves in coordination with the humerus. ${ }^{1,2}$ Serratus anterior (SA) with the upper (UT), middle (MT), and lower (LT) parts of the trapezius muscle work together in controlling normal scapular motion and providing stabilization. ${ }^{3}$ Specifically, excessive activation of the UT together with decreased activation of the LT, MT, and SA have been reported in patients with impingement syndrome ${ }^{4-6}$ and may contribute to the progress of impingement by altering scapular motion. ${ }^{5}$ Thereby, instead of global strengthening of the scapular muscles, restoration of the scapular muscle balance via the selective activation of the weaker muscles together with the minimal activation of the UT has been recommended for the rehabilitation of shoulder function. ${ }^{4,6,7}$

Closed kinetic chain (CKC) exercises are exercises where the distal segment is fixed and more proximal segments are free to move. ${ }^{8}$ These exercises are critical in rehabilitation as they promote muscular balance, coordination, and proprioception, which are all the critical components of early rehabilitation programs. ${ }^{9}$ They can also be progressed to mimic sports functions and may better prepare athletes for return to sport. ${ }^{10}$ The effects are thought to be produced

Karabay, Emük, and Özer Kaya are with the Department of Physiotherapy and Rehabilitation, Faculty of Health Sciences, İzmir Kâtip Çelebi Üniversitesi, Izmir, Turkey. Karabay and Emük are also with the Institute of Health Sciences, Dokuz Eylül University, Izmir, Turkey. Karabay (damla.gulpinar@ikc.edu.tr) is corresponding author. by reproducing the normal physiologic coactivations of the agonist/ antagonist muscles, thereby enhancing joint stability and providing normal motion patterns with minimal stress on the joints. ${ }^{10,11}$

Electromyography (EMG) allows the measurement of the muscle activity, and EMG studies are frequently used to guide rehabilitation programs designed for musculoskeletal injuries. ${ }^{12,13}$ Most CKC exercises, especially those involving push, generally reveal high SA activity, and thus may be recommended to restore muscle balance and shoulder function. ${ }^{14-17}$ However, the high activation of the SA may not be appropriate if the UT activation remains high during the given exercise, as muscle balance may not be restored and scapulohumeral function may not be improved. ${ }^{6,7}$ It is imperative to know this ratio to better decide whether a certain exercise should be prescribed or not. ${ }^{7}$ Moreover, despite their frequent use, pushing exercises are not the only form of shoulder CKC exercises 8,11 and relative activity of the SA (and also the MT and LT) to the UT is not comprehensively known. Scapular muscle ratios during open kinetic chain exercises have been previously studied and identified, ${ }^{13}$ but they have not been identified for CKC exercises.

\section{Objectives}

Therefore, the aim of this study was to identify CKC exercises that produce optimal muscle ratios of the scapular stabilizers in healthy shoulders. We believe that analyzing the extent to which shoulder CKC exercises promote optimal muscle ratios will be helpful for physiotherapists and other health professionals in the selection of appropriate exercises for selective muscle strengthening and restoration of scapular muscle balance. 


\section{Evidence Acquisition}

\section{Search Strategy}

A computerized, systematic search was conducted in January 2018 in the following databases: PubMed, Embase, CINAHL Plus with Full Text (EBSCO), SPORTDiscus with Full Text (EBSCO), and ULAKBIM National Medical Database. Terms were searched under 3 concepts: exercise, muscle (trapezius and SA), and EMG, and they were modified according to the specifications of each database (Appendix 1). The search was limited to studies published in English or Turkish and conducted in humans. However, there was no restriction for study type and publication date. One reviewer (Y.E.) imported all potentially relevant citations into EndNote reference management software (version X8.2; Thomson Reuters, New York, NY) and identified and removed duplicates. In addition, reference lists of studies included in full-text screening and were manually reviewed to identify additional studies.

\section{Study Selection}

Two reviewers (D.K. and Y.E.) independently performed an eligibility assessment using a prepiloted standardized form. First, the selection criteria were applied to the titles and abstracts. Then, full texts of all possible eligible studies were screened for inclusion in the review. A third reviewer (D.Ö.K.) was consulted in case of disagreement.

\section{Eligibility Criteria}

Studies were included if they were published as a full-text article in a peer-reviewed journal in English or Turkish, and included a group of participants with asymptomatic/healthy shoulders. To reduce the possible effects of shoulder pathology associated with aging, only studies involving participants with a mean age between 18 and 40 years were included. ${ }^{18}$

In line with the aim of the study, studies were required to use EMG as a primary tool to assess muscle activity of the UT with at least one of the following muscles: MT, LT, or SA. Only studies that reported the percentage of maximum voluntary isometric contraction (\%MVIC), the percentage maximum voluntary contraction, and/or the muscle ratios were included to provide standardization. For the reproducibility, comparability, and quality analysis purposes, studies were included if they described the detailed methods of EMG analysis and normalization procedure, including those stating the guidelines followed. All included studies were required to compare at least 2 actively performed CKC exercises for the same scapular muscles to provide a comparison. Studies which assessed individual phases (concentric, isometric, and eccentric) were included as long as they reported values for all phases of the performed exercises.

Studies were excluded if any of the eligibility criteria were not fulfilled. In addition, studies were excluded if all participants had a history of shoulder pathology/injury/pain or current/history of scapular pathology/symptoms within the past 2 years to reduce the potential effects of these factors on EMG activity. Furthermore, studies with no standardized procedure for normalization and analysis of EMG activity for all assessed muscles were excluded.

\section{Quality Assessment}

All included studies were assessed independently by 2 reviewers (D.K. and Y.E.) using an adapted version of a standardized quality assessment form for observational studies. ${ }^{19}$ This form was selected because it allows the assessment of each aspect of validity separately instead of a summarized score. It was adapted for this review using modified versions that were used in recent systematic reviews about EMG activity of shoulder muscles during rehabilitation exercises. ${ }^{6,12,13}$

\section{Data Extraction}

Two reviewers (D.K. and Y.E.) extracted relevant information about participant characteristics, methodology, the method of EMG analysis and normalization, exercises tested and result values (mean amplitude value or muscle ratios) using a specifically designed, and prepiloted form, then data extraction was checked by 1 reviewer (D.K.). When there was a disagreement, it was resolved by a third reviewer (D.Ö.K.).

It is considered that the use of resistance does not affect muscle ratios during the exercise. ${ }^{13}$ However, even CKC exercises without an extra load, could be difficult for the general population because body weight creates an axial load. ${ }^{20}$ If the same exercises were performed with and without resistance in a study, ${ }^{21}$ exercises without resistance were recorded for representing the general population. In addition, in studies comparing isometric exercises that used multiple intensities of force output, ${ }^{22}$ the maximal force was recorded for analyzing maximal \%MVIC due to the clinically more usable nature of maximum force during isometric exercises.

We calculated the ratios as UT/MT, UT/LT, and UT/SA using the \%MVIC of the relevant muscles for studies that did not obtain ratios. If \%MVIC or muscle ratio of individual phases were reported separately, the values were averaged to obtain a mean value for representing the entire exercise. Data were estimated from graphs in studies that reported their results graphically.

\section{Data Synthesis}

Because of discrepancies in EMG analysis methods, normalization procedures, exercises tested, and exercise procedures among studies, a meta-analysis was not conducted. ${ }^{23}$ A qualitative synthesis of the findings was performed to identify the muscle ratios elicited from each exercise. We reported pooled means of the ratios for exercises assessed in more than one study and an individual mean for those assessed in a single study. Exercises with muscle ratios $<1$ indicate that the EMG activities of the MT, LT, and SA are higher than that of the UT. According to the criteria determined by Cools et al, ${ }^{7}$ ratios $<0.60$ were considered as excellent for the aim of this review. Finally, exercises with muscle ratios $>1$ indicate that the UT was more active than the other scapular stabilizers.

\section{Evidence Synthesis}

\section{Study Selection}

The systematic search identified 1284 studies, of which 84 were assessed in full text, and 29 were included for review after screening for eligibility (Figure 1).

\section{Study Characteristics and Methodological Quality}

All included studies were cross-sectional designs. One of them ${ }^{22}$ was a reliability study with test-retest values, and only the test values (rather than retest values) were included in the analysis. Male participants were predominant $(66 \%)$. Fourteen studies ${ }^{15,21,22,24-34}$ included only males and one study ${ }^{14}$ included only females. Furthermore, 3 studies $^{32,35,36}$ specifically included athletes as participants, and one study ${ }^{21}$ 


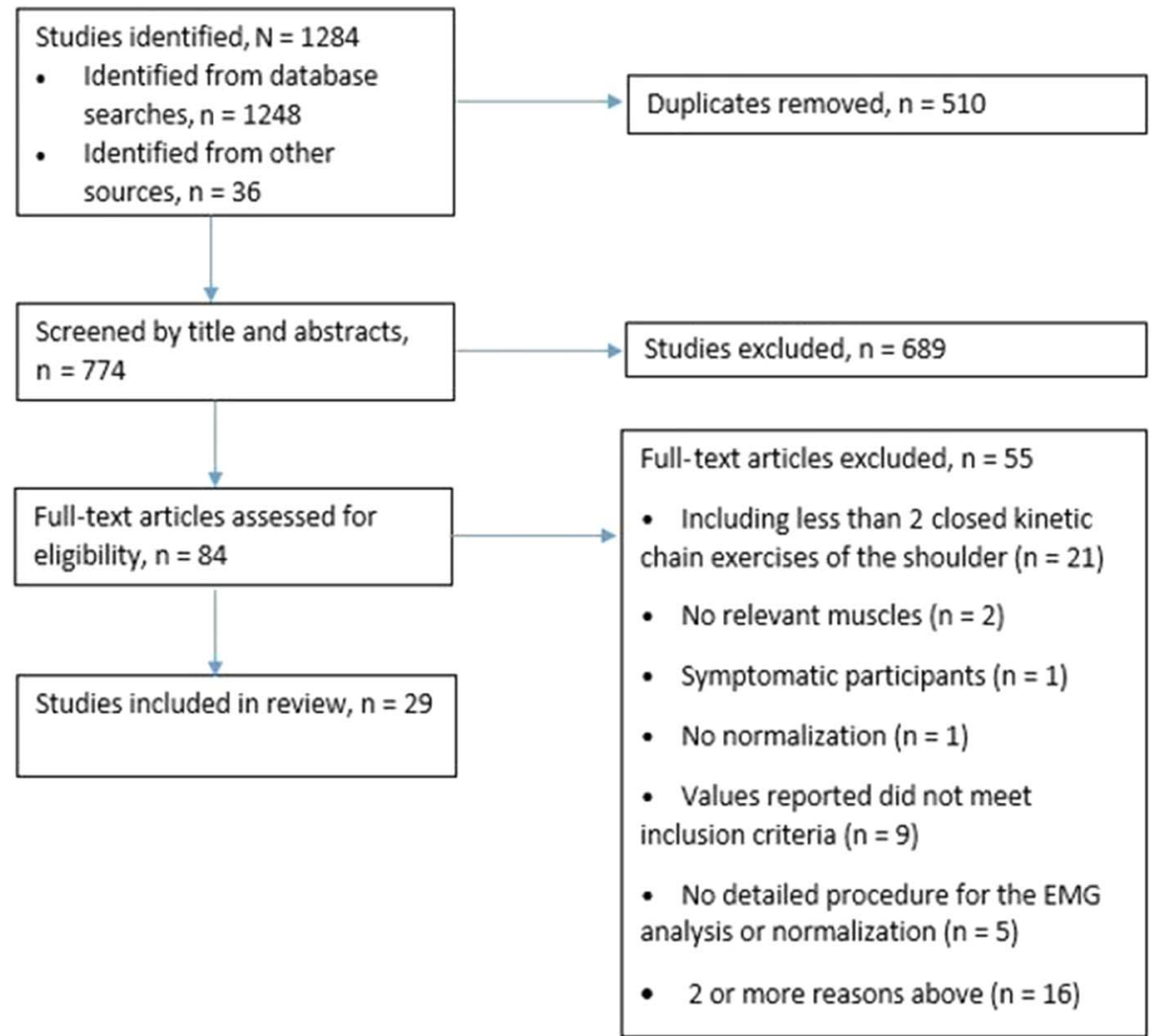

Figure 1 - Flowchart of study selection process. EMG indicates electromyography.

included participants who were considered as advanced in resistance training.

All included participants completed the study protocols with no dropout. Eight of the included studies $15,22,24,26,27,31,35,37$ performed a physical examination by a medical professional before testing, and only 2 studies ${ }^{25,28}$ controlled for the presence of scapular dyskinesis. The absence of these examinations may reduce internal validity. However, it is not known how much dyskinesis is pathological $^{38}$ and the results of this study may still be very relevant to many subjects who have noted dyskinesis but no shoulder pain. All subjects were pain free in our included studies. Blinding of the assessors during testing was not undertaken in any of the studies because of the observational nature of the EMG analysis.

All but $12^{16,17,20,25,28,29,33,35,36,39-41}$ of the included studies performed exercises using standardized speed and phase durations. All included studies performed appropriate normalization of raw EMG data. Randomization of the exercises was performed in all studies except one ${ }^{30}$; however, randomization of MVICs was not frequent, and this may affect the internal validity of the results. Summaries of the characteristics and methodological quality for each study were presented in Tables 1 and 2, respectively.

\section{Muscle Ratios}

This review identified a total of 81 CKC exercises classified according to their biomechanics (Appendix 2). Among the included studies, EMG activity of the UT was recorded together with the MT during 33 exercises, with the LT during 57 exercises, and with the SA during 79 exercises. Pooled means of the UT/MT, UT/LT, and UT/SA are presented in Figures 2 to 4, respectively. Overall, UT/MT was $<1$ for 11 exercises, UT/LT was $<1$ for 24 exercises, and UT/SA was $<1$ for 71 exercises, indicating less activation of the UT compared with the other scapular stabilizers. Consequently, 4 exercises for the MT, 9 for the LT, and 59 for the SA were identified as excellent exercises, with ratios $<0.60$, to activate the specified muscles more than the UT.

\section{Discussion}

This review highlights the activity ratios of the scapular stabilizer muscles during common $\mathrm{CKC}$ exercises to help guide health professionals in exercise selection when prescribing rehabilitation programs. Restoration of the muscular imbalance via exercises that inhibit UT activity and facilitating the MT, LT, and SA rather than strengthening all scapular muscles is highly recommended by researchers. ${ }^{7,37}$ To determine the optimal exercises for selective strengthening of the scapular muscles, a ratio of at least 0.60 is warranted. $^{7}$ In this review, the pooled means of 4,9 , and 59 exercises for the UT/MT, UT/LT, and UT/SA, respectively, demonstrated that ratios were below 0.60 . The results of this review suggest that most of the $\mathrm{CKC}$ exercises are optimal exercises for selective activation of the SA, whereas some of them are optimal for selective activation of the MT and LT. All exercises that fall below the 0.60 ratio may be beneficial in restoring scapular muscle imbalance.

Isometric low row (Figure 5A) and inferior glide (Figure 5B) exercises are recommended in early to mid stages of shoulder rehabilitation, because they reveal a low to moderate level of EMG activity in shoulder and scapular muscles. ${ }^{46,47}$ In this review, these exercises had excellent UT/MT, UT/LT, and UT/SA ratios, making them optimal selections to restore muscular balance of the 


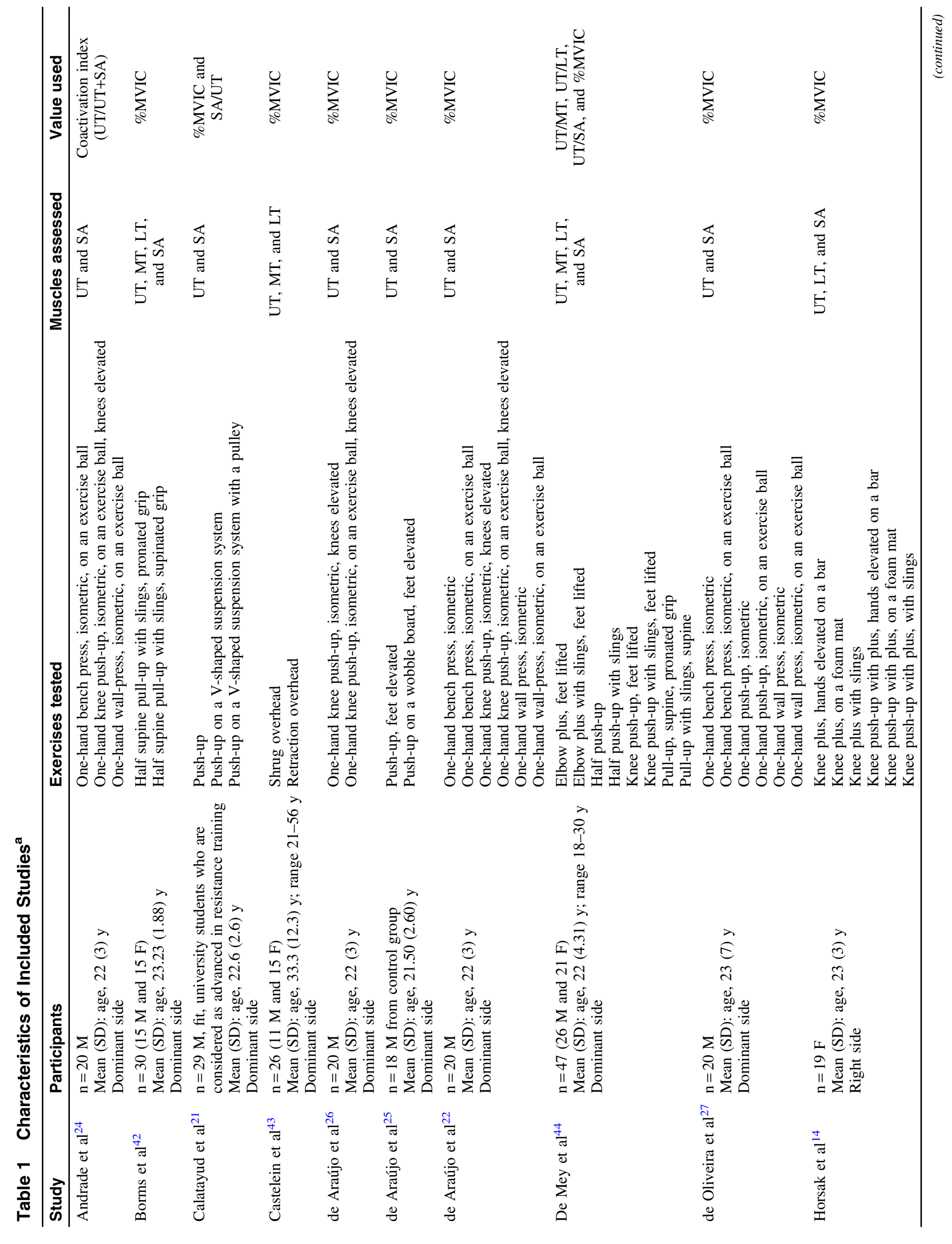




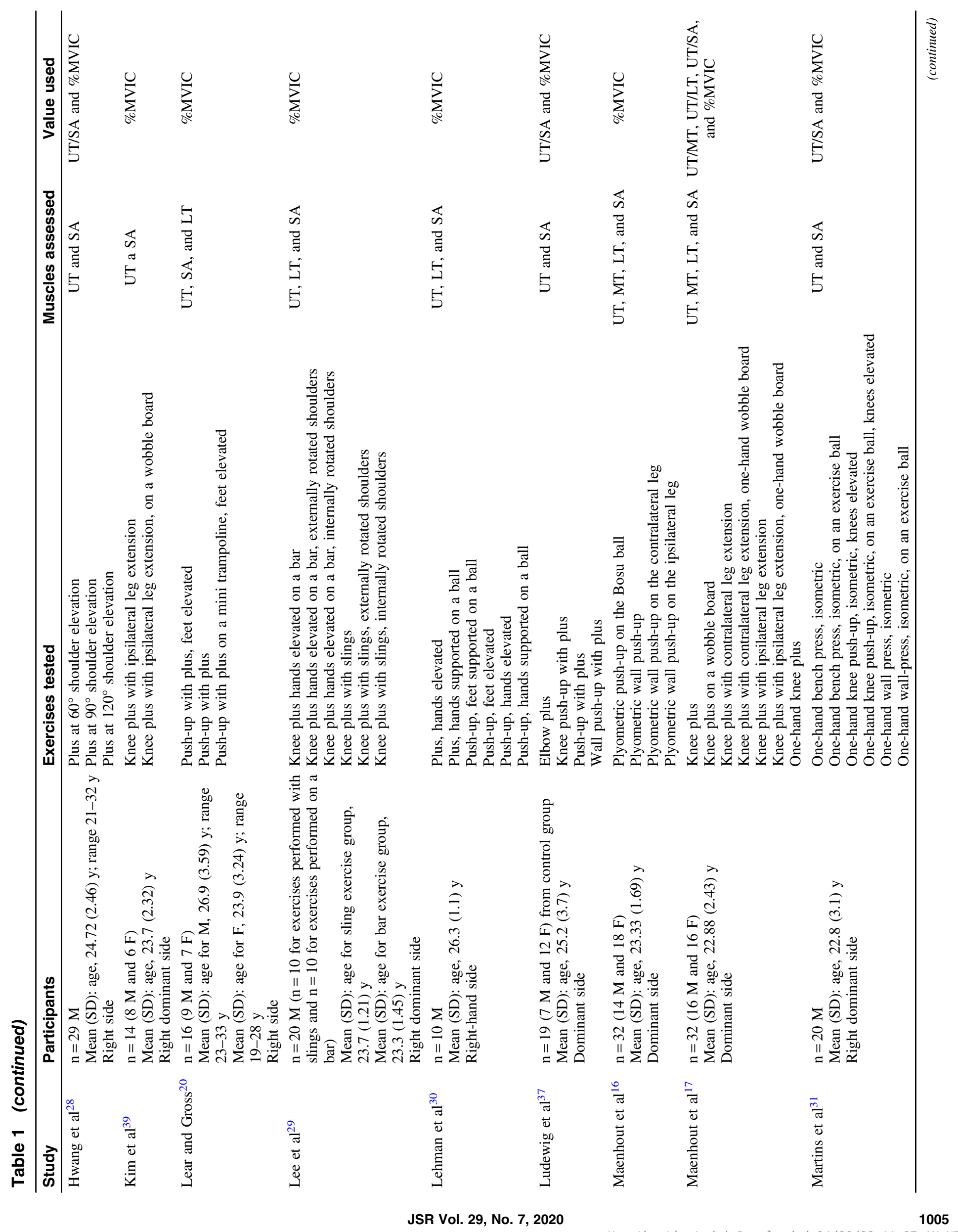




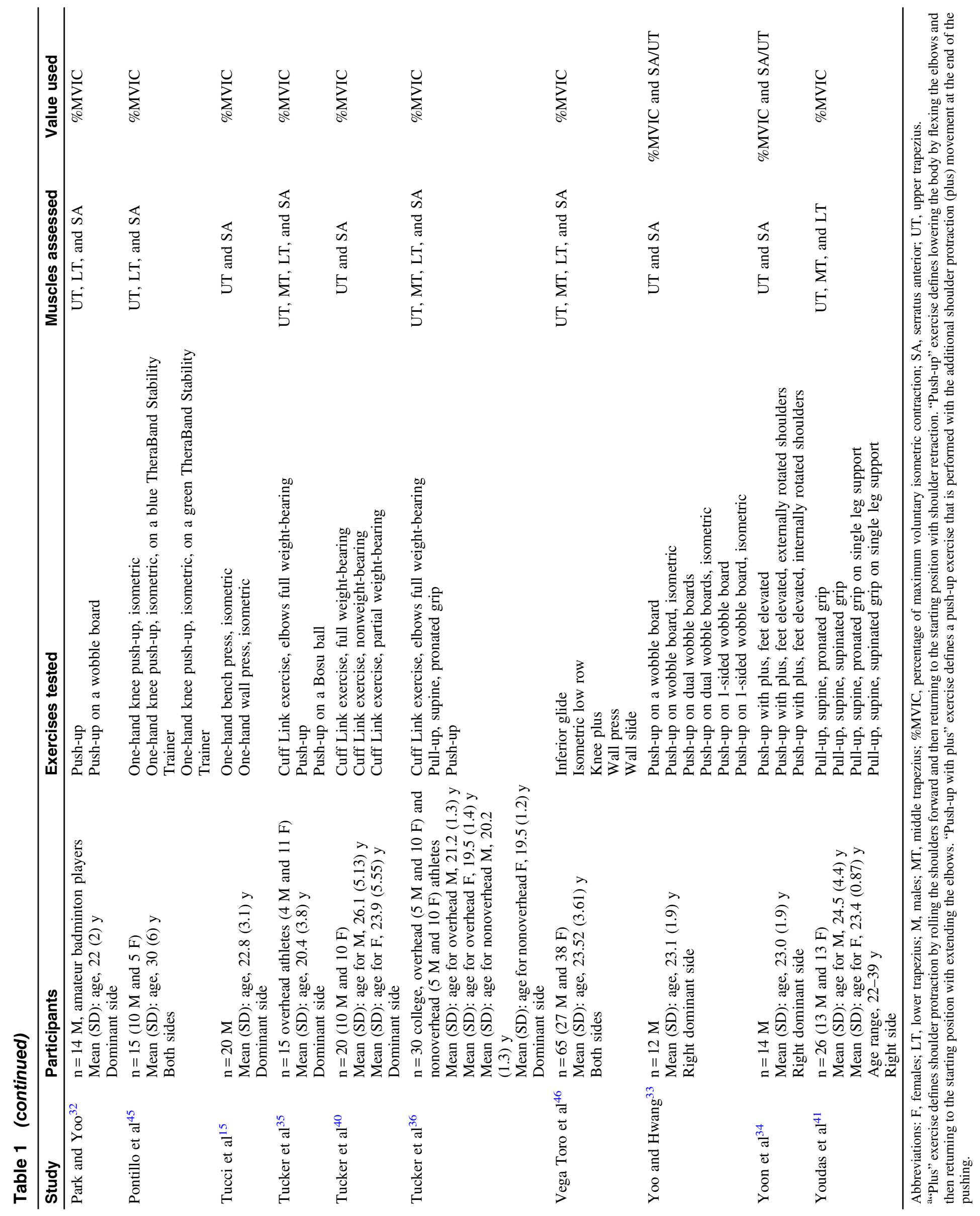




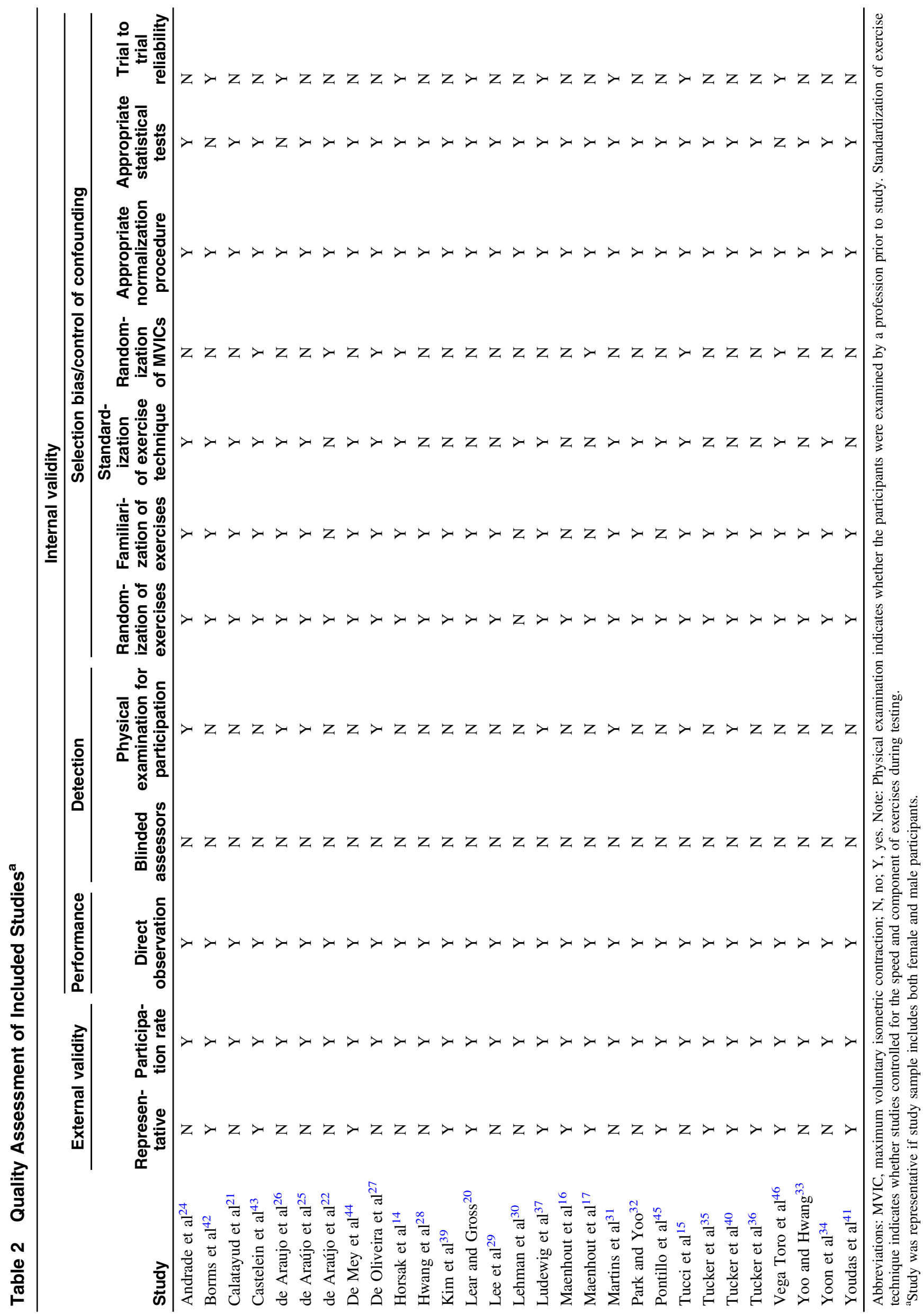




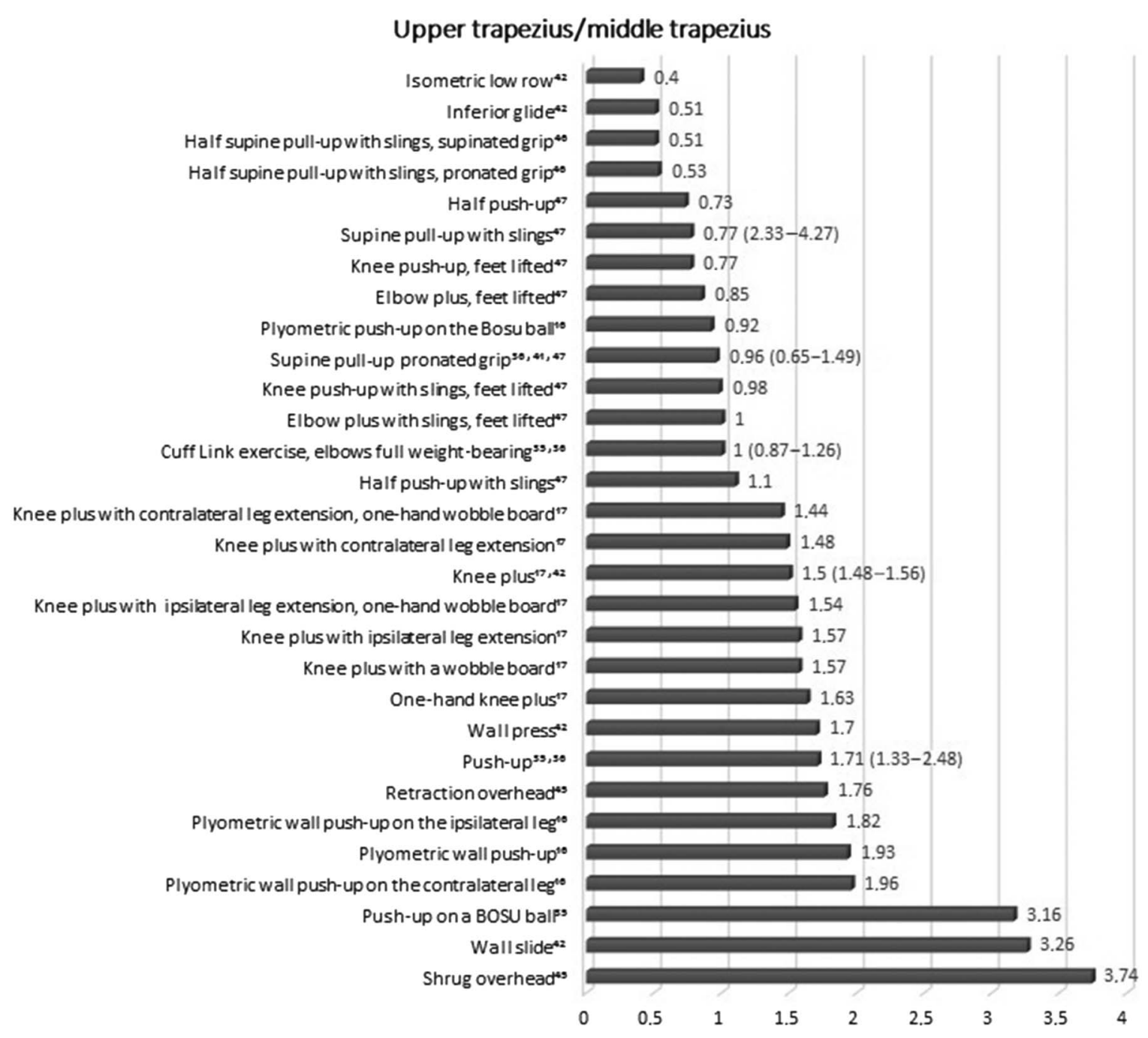

Figure 2 - Pooled means (range) of upper/middle trapezius ratios.

shoulder girdle. These exercises focused on a combination of scapular adduction and depression, which is the opposite of the UT function, ${ }^{48}$ and could be the first choice for reducing excessive activation of the UT. Although they were assessed only in one study, ${ }^{46}$ Kibler et $\mathrm{l}^{47}$ reported low UT activity with relatively high LT and SA activity (more than 1.5 times) during these exercises in both symptomatic and asymptomatic shoulders.

The use of the shrug exercise performed as an open kinetic chain was not recommended by Schory et $\mathrm{al}^{13}$ because of excessive activity of the UT relative to other scapular stabilizers. Similarly, in this review, shrug overhead (the CKC form) ${ }^{43}$ had the worst ratio in UT/MT and higher UT activity than LT activity. Therefore, we do not recommend prescribing the shrug overhead exercise with the aim of activating the MT and LT. However, none of the studies in our review assessed the activity of the UT and SA together during shrug overhead; therefore, the UT/SA ratio for this exercise is still unknown.

Even though push-up was the most common exercise utilized, none of the variations produced optimal UT/MT ratios. Only the half push-up and knee push-up with lifted feet exercises revealed good muscle ratios $(0.60-0.80)^{7}$ in UT/MT. Although pull-up exercises are not as common as push-ups in the clinical setting, it was found in this review that all 3 muscle ratios were excellent during half supine pull-ups with slings (Figure 5C). ${ }^{42}$ This exercise may be an option for the restoration of scapular muscle imbalance by selective strengthening of the MT, LT, and SA. However, the results of this exercise were obtained in only one study. ${ }^{42}$ Therefore, this suggestion should be interpreted with caution. In addition, this review found that the UT was less active than the MT and LT during the supine pull-up with a pronated grip exercise. ${ }^{36,41,44}$ However, this exercise had the worst muscle ratios in UT/SA. ${ }^{36,44}$ In this CKC position, the gravitational force will pull the scapula into protraction, and the pronated position of the forearm may force the scapula more upward rotation, anterior tilt, and protraction ${ }^{49}$ and probably feed into a more forward head-shoulder position. ${ }^{50}$ Therefore, the already protracted position of the scapula may be the reason for the high UT/SA ratio by less activation of the SA during supine pull-ups with a pronated grip.

In terms of UT/LT ratio, isometric one-hand knee push-ups (Figure 5D), ${ }^{45}$ irrespective of the surface, had excellent ratios. Moreover, among isotonic push-up variations, excellent ratios for UT/LT were determined in only plus and push-up exercises both with elevated hands. ${ }^{30}$ The elevated position of the hand (from the floor) may lead to lower humeral elevation angles, and this could 


\section{Upper trapezius/lower trapezius}

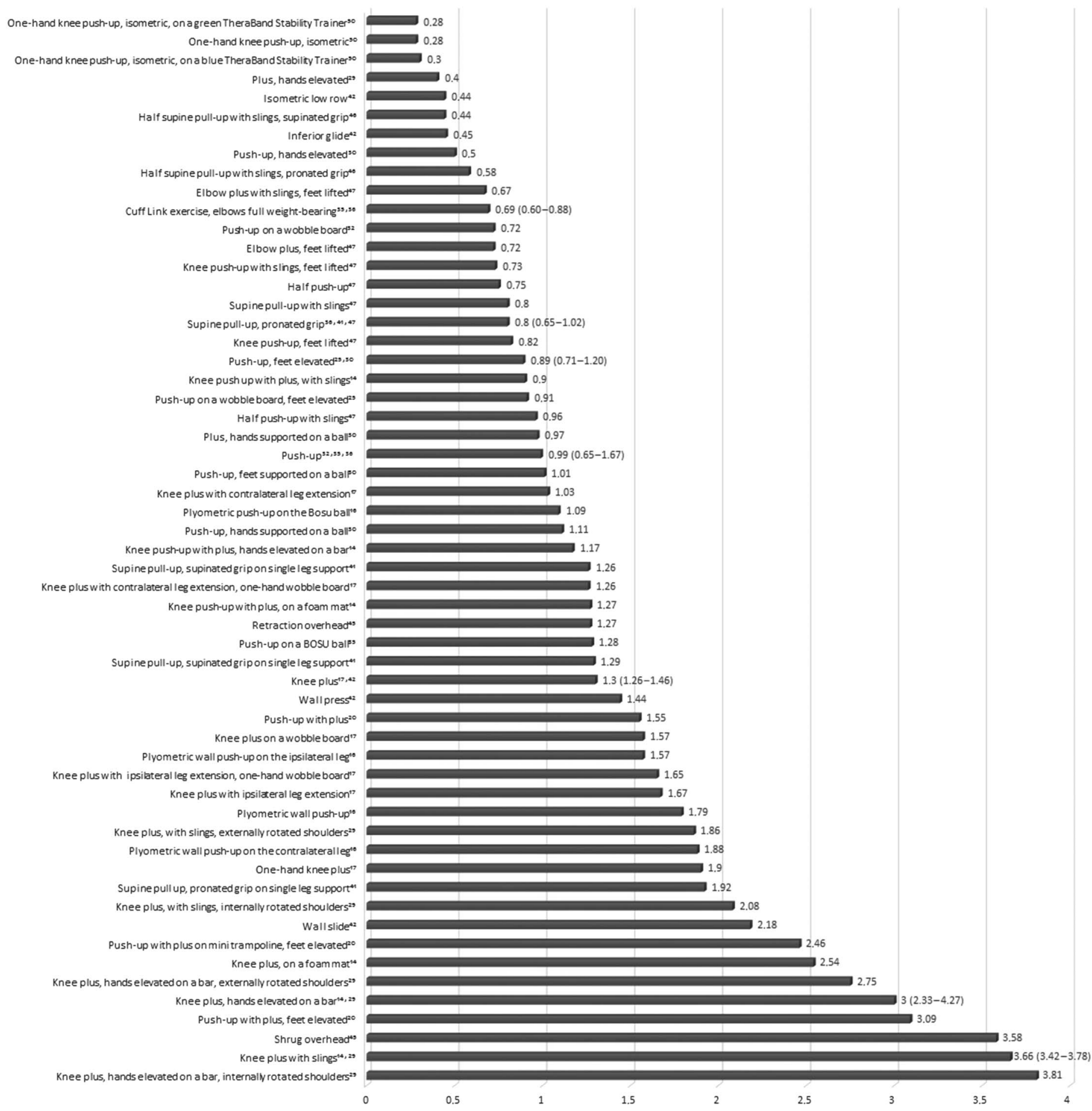

Figure 3 - Pooled means (range) of upper/lower trapezius ratios.

force the scapula to more anterior tilt, and internal and downward rotation. ${ }^{51}$ To counter these forces, an increase in the LT activity with a decrease in the UT activity may have occurred and created more optimal ratios of the UT/LT in these exercises. However, it is difficult to draw definitive conclusions because not all CKC exercises which were performed with the elevated position of the arms had good ratios, and exercises mentioned above were assessed only in individual studies. ${ }^{30,45}$ In addition, it was determined in this review that all variations of knee plus exercises had ratios approximate to or $>1$ for UT/LT and UT/MT. The relatively low load on the arms in the kneeling position and little movement in the upper extremities during the plus movement may have affected 
Upper trapezius/serratus anterior

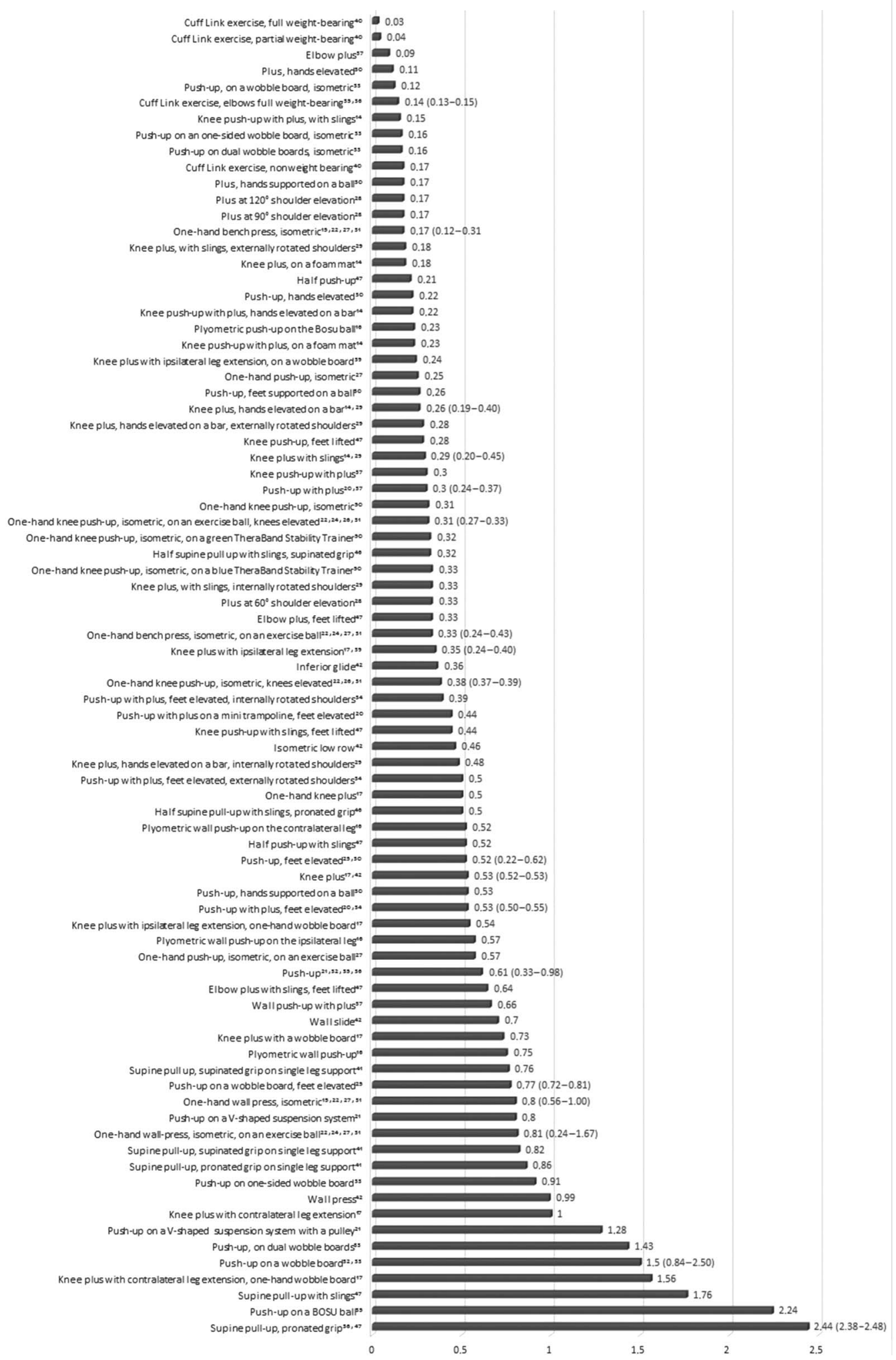

Figure 4 - Pooled means (range) of upper trapezius/serratus anterior ratios.

the MT and LT activities ${ }^{37}$ via decreasing stabilization function of these muscles during scapular protraction. We do not recommend using the knee plus exercises for restoring the muscular imbalance between parts of the trapezius.
Our search strategy yielded mostly pushing exercises including the push-up, plus, press, and bench press variations. Therefore, this review revealed that the SA was the most active muscle among these scapular stabilizers with optimal UT/SA ratios during many 

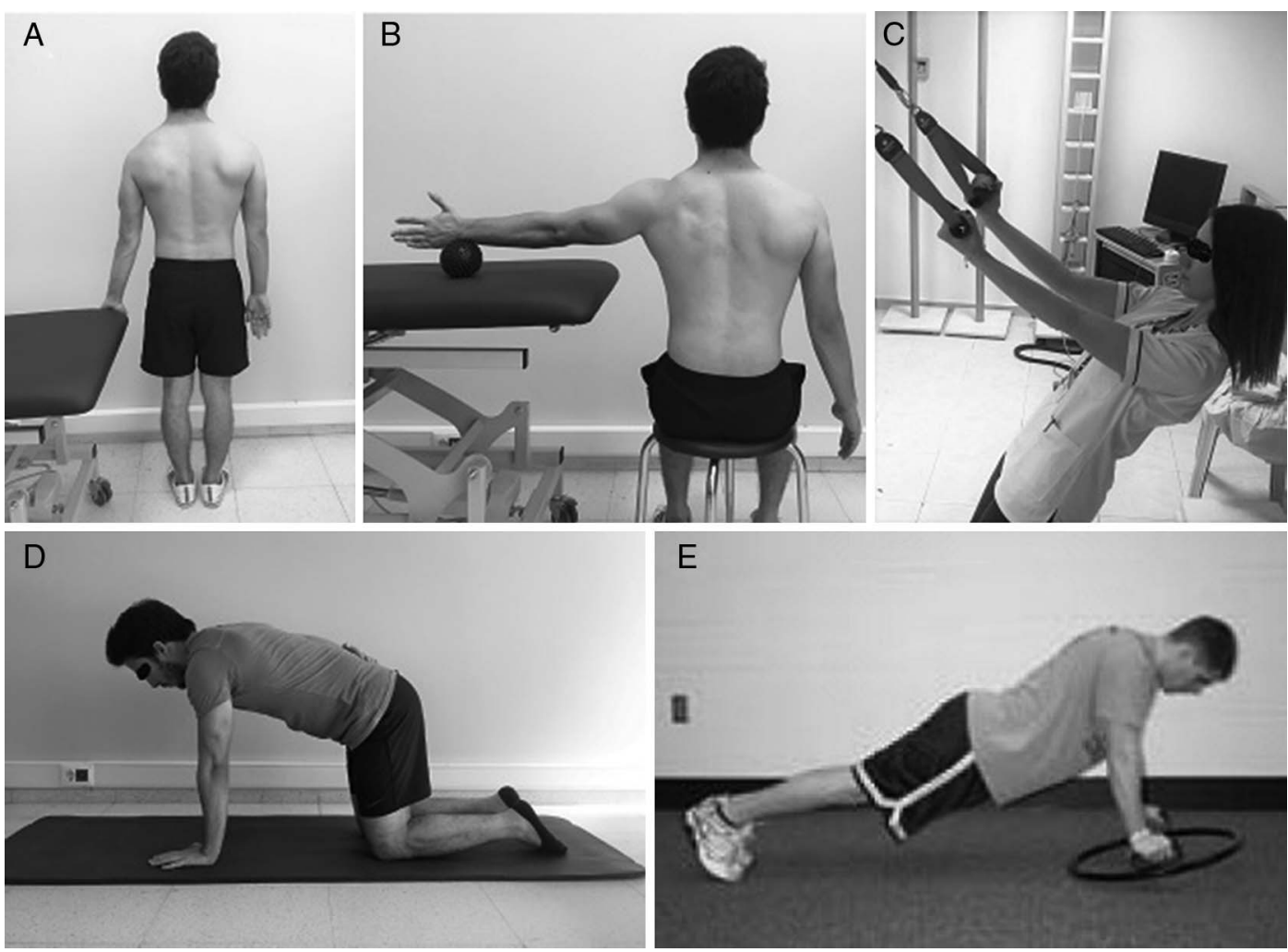

Figure 5 - Closed kinetic chain exercises. (A) Isometric low row. (B) Inferior glide. (C) Half supine pull-up. (D) Isometric one-hand knee push-up. (E) Cuff Link exercise, full weight-bearing. (Reprinted from Tucker et $\mathrm{al}^{40}$ by permission of Human Kinetics.).

of the exercises reviewed. Although the Cuff Link exercise does not have frequent use clinically, the present review found that the Cuff Link exercises in different weight-bearing conditions s $^{35,36,40}$ may be appropriate for the restoration of the muscle imbalance between the SA and UT because they had the lowest UT/SA ratios $(<0.20)$, especially in partial and full weight-bearing conditions (Figure 5E). ${ }^{40}$ In this review, the pooled means of UT/MT and UT/LT for the Cuff Link exercise were calculated only when the position of the elbows was full weight-bearing..$^{35,36}$ UT and MT activation levels were similar and the LT activity was higher than those of the other parts of the trapezius for this exercise. During the other variations of the Cuff Link exercises, the EMG activity of the MT and LT together with the UT should be investigated in further studies to derive more precise conclusions.

Another interesting finding of this review was that all of the pushing exercises with a UT/SA ratio $>1$ were performed on unstable surfaces. Seven CKC exercises had UT/SA ratios $>1$, and 4 of them were pushing exercises performed on unstable surfaces. Besides, most of the pushing exercises performed on unstable surfaces ( 33 of 37 exercises) had optimal ratios. Therefore, if the aim is higher activation of the SA rather than the UT, caution should be taken when prescribing CKC exercises on unstable surfaces.

Previous researchers have mentioned excessive activation of the UT during open kinetic chain exercises in a standing position because of gravity. ${ }^{7}$ In this review, wall exercises performed in a standing position had UT/SA ratios $>0.60$, and UT/MT and UT/LT ratios $>1.00$. Wall CKC exercises, such as wall slides and presses, are prescribed in the early stages of the rehabilitation because they have lower joint loads compared with CKC exercises performed in prone positions. ${ }^{37}$ Thus, the research suggests that standing wall slides/presses/push-ups may not be appropriate in the early stages of rehabilitation if the primary goal is to achieve a low UT/SA ratio. Still, these exercises may be appropriate in other instances, and the clinician should have a good understanding of the desired goal when prescribing these exercises as part of a comprehensive rehabilitation program.

\section{Limitations}

The results of this review are based on a population with healthy, asymptomatic shoulders. Although UT/SA ratios in patients with shoulder dysfunction have been reported to be similar to those of asymptomatic controls during some push-up variations in one study, ${ }^{37}$ for other types of CKC exercises, whether muscle ratios are different between patients and healthy individuals is still unclear. Nonetheless, these results serve as a good basis for rehabilitation programs for patients with scapular muscle imbalance. However, they should be verified by further studies in symptomatic shoulders.

Many studies have reported only \%MVICs. Calculating values from \%MVICs rather than original ratios could lead to a deviation from the true value. A few studies have reported eccentric and concentric phase values separately and averaging these may also cause errors. Ekstrom et $\mathrm{al}^{52}$ observed that 2 parts of the SA had a similar EMG activity during maximum scapular protraction positions including push-ups. In this review, electrode placement locations varied among studies, and some studies evaluated both upper parts of the SA, whereas some other studies evaluated the 
lower parts. However, 2 studies ${ }^{25,32}$ have evaluated the lower and upper parts of the SA separately, rather than using 1 electrode placement area for the SA. Therefore, we analyzed both parts of the SA and pooled these results together for these 2 studies. Differences between studies in the methodology of EMG analysis and normalization, exercise procedures, and inclusion criteria of participants may have affected the results of this review. However, although it is difficult to find studies in which similar procedures of EMG and exercise have been implemented, the inclusion of the studies which have performed EMG normalization and classification of the exercises according to their biomechanics provided us a considerable standardization. Finally, many exercises in this review have been evaluated only in a single study each. Therefore, results must be interpreted with caution for a comparison between these exercises because of the methodological differences between studies.

\section{Conclusions}

This review identified the optimal CKC exercises and also those that should be avoided for the restoration of the scapular muscle imbalance in healthy, asymptomatic shoulders. Most CKC exercises tend to activate the SA higher than the UT, and specifically the Cuff Link exercises have the best ratios for the UT/SA. Although there were a few optimal exercise choices for the MT and LT, this review presents CKC exercises that could be used by therapists for the selective strengthening of the MT and LT in the early stages of the rehabilitation process where CKC exercises may be more preferred than the open kinetic chain. ${ }^{9}$ For selective activation of the MT, the isometric low row, inferior glide, and half supine pull-up with slings are the ideal exercises. The isometric one-hand knee push-up variations are the best choice for the LT. Inferior glide, isometric low row, and half supine pull-ups with slings could be the best exercises for high activation of all MT, LT, and SA together with the inhibition of the UT. Some forms of the push-ups or pluses on unstable surfaces may lead to excessive activation of the UT relative to the SA. Moreover, we do not recommend wall CKC exercises for restoring scapular muscle imbalance because of higher activation of the UT compared with the other scapular stabilizers. This review provides a good basis for the guidance of rehabilitation programs conducted clinically and the results of this review should be further investigated in patients with scapular muscle imbalance to determine the effects on ratios and functional outcomes.

\section{Acknowledgment}

The authors have no conflicts of interest to disclose.

\section{References}

1. Ludewig PM, Phadke V, Braman JP, Hassett DR, Cieminski CJ, LaPrade RF. Motion of the shoulder complex during multiplanar humeral elevation. J Bone Joint Surg Am. 2009;91(2):378-389. PubMed ID: 19181982 doi:10.2106/JBJS.G.01483

2. Meyer KE, Saether EE, Soiney EK, Shebeck MS, Paddock KL, Ludewig PM. Three-dimensional scapular kinematics during the throwing motion. J Appl Biomech. 2008;24(1):24-34. PubMed ID: 18309180 doi:10.1123/jab.24.1.24

3. Bagg SD, Forrest WJ. Electromyographic study of the scapular rotators during arm abduction in the scapular plane. Am J Phys Med. 1986;65(3):111-124. PubMed ID: 3717317
4. Cools AM, Declercq GA, Cambier DC, Mahieu NN, Witvrouw EE. Trapezius activity and intramuscular balance during isokinetic exercise in overhead athletes with impingement symptoms. Scand J Med Sci Sports. 2007;17(1):25-33. PubMed ID: 16774650

5. Ludewig PM, Cook TM. Alterations in shoulder kinematics and associated muscle activity in people with symptoms of shoulder impingement. Phys Ther. 2000;80(3):276-291. PubMed ID: 10696154

6. Kinsella R, Pizzari T. Electromyographic activity of the shoulder muscles during rehabilitation exercises in subjects with and without subacromial pain syndrome: a systematic review. Shoulder Elbow. 2017;9(2):112-126. PubMed ID: 28405223 doi:10.1177/ 1758573216660038

7. Cools AM, Dewitte V, Lanszweert F, et al. Rehabilitation of scapular muscle balance: which exercises to prescribe? Am J Sports Med. 2007;35(10):1744-1751. PubMed ID: 17606671 doi:10.1177/ 0363546507303560

8. Kibler WB, Livingston B. Closed-chain rehabilitation for upper and lower extremities. J Am Acad Orthop Surg. 2001;9(6):412-421. PubMed ID: 11730332 doi:10.5435/00124635-200111000-00006

9. Wright AA, Hegedus EJ, Tarara DT, Ray SC, Dischiavi SL. Exercise prescription for overhead athletes with shoulder pathology: a systematic review with best evidence synthesis. Br J Sports Med. 2018;52(4):231-237. PubMed ID: 28404557 doi:10.1136/bjsports2016-096915

10. Prokopy MP, Ingersoll CD, Nordenschild E, Katch FI, Gaesser GA, Weltman A. Closed-kinetic chain upper-body training improves throwing performance of NCAA Division I softball players. J Strength Cond Res. 2008;22(6):1790-1798. PubMed ID: 18978626 doi:10.1519/JSC. 0b013e318185f637

11. Kibler WB. The role of the scapula in athletic shoulder function. Am J Sports Med. 1998;26(2):325-337. PubMed ID: 9548131 doi:10. 1177/03635465980260022801

12. Edwards PK, Ebert JR, Littlewood C, Ackland T, Wang A. A systematic review of electromyography studies in normal shoulders to inform postoperative rehabilitation following rotator cuff repair. J Orthop Sports Phys Ther. 2017;47(12):931-944. PubMed ID: 28704624 doi:10.2519/jospt.2017.7271

13. Schory A, Bidinger E, Wolf J, Murray L. A systematic review of the exercises that produce optimal muscle ratios of the scapular stabilizers in normal shoulders. Int J Sports Phys Ther. 2016;11(3):321-336. PubMed ID: 27274418

14. Horsak B, Kiener M, Potzelsberger A, Siragy T. Serratus anterior and trapezius muscle activity during knee push-up plus and knee-plus exercises performed on a stable, an unstable surface and during slingsuspension. Phys Ther Sport. 2017;23:86-92. PubMed ID: 27693098 doi:10.1016/j.ptsp.2016.08.003

15. Tucci HT, Ciol MA, de Araujo RC, et al. Activation of selected shoulder muscles during unilateral wall and bench press tasks under submaximal isometric effort. J Orthop Sports Phys Ther. 2011;41(7):520-525. PubMed ID: 21289450 doi:10.2519/jospt. 2011.3418

16. Maenhout A, Benzoor M, Werin M, Cools A. Scapular muscle activity in a variety of plyometric exercises. J Electromyogr Kinesiol. 2016;27:39-45. PubMed ID: 26894494 doi:10.1016/j.jelekin.2016. 01.003

17. Maenhout A, Van Praet K, Pizzi L, Van Herzeele M, Cools A. Electromyographic analysis of knee push up plus variations: what is the influence of the kinetic chain on scapular muscle activity? $\mathrm{Br} \mathrm{J}$ Sports Med.2010;44(14):1010-1015. PubMed ID: 19752153 doi:10. 1136/bjsm.2009.062810

18. Milgrom C, Schaffler M, Gilbert S, van Holsbeeck M. Rotator-cuff changes in asymptomatic adults. The effect of age, hand dominance 
and gender. J Bone Joint Surg Br. 1995;77(2):296-298. PubMed ID: 7706351 doi:10.1302/0301-620X.77B2.7706351

19. Siegfried N, Muller M, Deeks J, et al. HIV and male circumcision-a systematic review with assessment of the quality of studies. Lancet Infect Dis. 2005;5(3):165-173. PubMed ID: 15766651 doi:10.1016/ S1473-3099(05)70024-4

20. Lear LJ, Gross MT. An electromyographical analysis of the scapular stabilizing synergists during a push-up progression. J Orthop Sports Phys Ther. 1998;28(3):146-157. PubMed ID: 9742471 doi:10.2519/ jospt.1998.28.3.146

21. Calatayud J, Borreani S, Colado JC, Martin F, Rogers ME. Muscle activity levels in upper-body push exercises with different loads and stability conditions. Phys Sportsmed. 2014;42(4):106-119. PubMed ID: 25419894 doi:10.3810/psm.2014.11.2097

22. de Araujo RC, Tucci HT, de Andrade R, Martins J, Bevilaqua-Grossi $\mathrm{D}$, de Oliveira AS. Reliability of electromyographic amplitude values of the upper limb muscles during closed kinetic chain exercises with stable and unstable surfaces. J Electromyogr Kinesiol. 2009;19(4): 685-694. PubMed ID: 18234507 doi:10.1016/j.jelekin.2007.11.014

23. Egger M, Schneider M, Davey Smith G. Spurious precision? Metaanalysis of observational studies. BMJ. 1998;316(7125):140-144. PubMed ID: 9462324 doi:10.1136/bmj.316.7125.140

24. Andrade R, Araujo RC, Tucci HT, Martins J, Oliveira AS. Coactivation of the shoulder and arm muscles during closed kinetic chain exercises on an unstable surface. Singapore Med J. 2011;52(1):3541. PubMed ID: 21298239

25. de Araujo RC, Piraua ALT, Beltrao NB, Pitangui ACR. Activity of periscapular muscles and its correlation with external oblique during push-up: does scapular dyskinesis change the electromyographic response? J Sports Sci. 2018;36(5):571-577. PubMed ID: 28537843 doi:10.1080/02640414.2017.1324205

26. de Araujo RC, de Andrade R, Tucci HT, Martins J, de Oliveira AS. Shoulder muscular activity during isometric three-point kneeling exercise on stable and unstable surfaces. J Appl Biomech. 2011;27(3):192196. PubMed ID: 21844607 doi:10.1123/jab.27.3.192

27. de Oliveira AS, de Morais Carvalho M, de Brum DP. Activation of the shoulder and arm muscles during axial load exercises on a stable base of support and on a medicine ball. J Electromyogr Kinesiol. 2008;18(3):472-479. PubMed ID: 17218116 doi:10.1016/j.jelekin. 2006.09.009

28. Hwang UJ, Kwon OY, Jeon IC, Kim SH, Weon JH. Effect of humeralelevation angle on electromyographic activity in the serratus anterior during the push-up-plus exercise. J Sport Rehabil. 2017;26(1):57-64. PubMed ID: 27632840 doi:10.1123/jsr.2015-0090

29. Lee S, Lee D, Park J. The effect of hand position changes on electromyographic activity of shoulder stabilizers during push-up plus exercise on stable and unstable surfaces. J Phys Ther Sci. 2013; 25(8):981-984. PubMed ID: 24259898 doi:10.1589/jpts.25.981

30. Lehman GJ, Gilas D, Patel U. An unstable support surface does not increase scapulothoracic stabilizing muscle activity during push up and push up plus exercises. Man Ther. 2008;13(6):500-506. PubMed ID: 17643339 doi:10.1016/j.math.2007.05.016

31. Martins J, Tucci HT, Andrade R, Araujo RC, Bevilaqua-Grossi D, Oliveira AS. Electromyographic amplitude ratio of serratus anterior and upper trapezius muscles during modified push-ups and bench press exercises. J Strength Cond Res. 2008;22(2):477-484. PubMed ID: 18550963 doi:10.1519/JSC.0b013e3181660748

32. Park S-Y, Yoo W-G. Effects of push-up exercise phase and surface stability on activation of the scapulothoracic musculature. Int J Athl Ther Train. 2013;18(4):34-38. doi:10.1123/ijatt.18.4.34

33. Yoo W-G, Hwang Y-I. Activation and ratio of the upper trapezius and serratus anterior muscles during dynamic and isometric exercises on various support surfaces. J Phys Ther Sci. 2010;22(3):267-271. doi:10.1589/jpts.22.267

34. Yoon J-Y, Kim T-H, Oh J-S. Effects of hand positions on electromyographic activity in scapulothoracic muscles during push-up plus. Phys Ther Korea. 2010;17(4):8-15.

35. Tucker WS, Armstrong CW, Gribble PA, Timmons MK, Yeasting RA. Scapular muscle activity in overhead athletes with symptoms of secondary shoulder impingement during closed chain exercises. Arch Phys Med Rehabil. 2010;91(4):550-556. PubMed ID: 20382286 doi:10.1016/j.apmr.2009.12.021

36. Tucker WS, Bruenger AJ, Doster CM, Hoffmeyer DR. Scapular muscle activity in overhead and nonoverhead athletes during closed chain exercises. Clin J Sport Med. 2011;21(5):405-410. PubMed ID: 21814139 doi:10.1097/JSM.0b013e31822179e8

37. Ludewig PM, Hoff MS, Osowski EE, Meschke SA, Rundquist PJ. Relative balance of serratus anterior and upper trapezius muscle activity during push-up exercises. Am J Sports Med. 2004;32(2):484-493. PubMed ID: 14977678 doi:10.1177/0363546503258911

38. Kibler WB, Ludewig PM, McClure PW, Michener LA, Bak K, Sciascia AD. Clinical implications of scapular dyskinesis in shoulder injury: the 2013 consensus statement from the "Scapular Summit." Br J Sports Med. 2013;47(14):877-885. PubMed ID: 23580420 doi:10.1136/bjsports-2013-092425

39. Kim J-B, Choi I-R, Yoo W-G. A comparison of scapulothoracic and trunk muscle activities among three variations of knee push-upplus exercises. J Phys Ther Sci. 2011;23(3):365-367. doi:10.1589/jpts. 23.365

40. Tucker WS, Armstrong CW, Swartz EE, Campbell BM, Rankin JM. An electromyographic analysis of the cuff link rehabilitation device. J Sport Rehabil. 2005;14(2):124-136. doi:10.1123/jsr.14. 2.124

41. Youdas JW, Keith JM, Nonn DE, Squires AC, Hollman JH. Activation of spinal stabilizers and shoulder complex muscles during an inverted row using a portable pull-up device and body weight resistance. J Strength Cond Res. 2016;30(7):1933-1941. PubMed ID: 26422610 doi:10.1519/JSC.0000000000001210

42. Borms D, Ackerman I, Smets P, Van den Berge G, Cools AM. Biceps disorder rehabilitation for the athlete: a continuum of moderate- to high-load exercises. Am J Sports Med. 2017;45(3):642-650. PubMed ID: 28125910 doi:10.1177/0363546516674190

43. Castelein B, Cools A, Parlevliet T, Cagnie B. Modifying the shoulder joint position during shrugging and retraction exercises alters the activation of the medial scapular muscles. Man Ther. 2016;21:250 255. PubMed ID: 26409441 doi:10.1016/j.math.2015.09.005

44. De Mey K, Danneels L, Cagnie B, et al. Shoulder muscle activation levels during four closed kinetic chain exercises with and without Redcord slings. J Strength Cond Res. 2014;28(6):1626-1635. PubMed ID: 24172720 doi:10.1519/JSC.0000000000000292

45. Pontillo M, Orishimo KF, Kremenic IJ, McHugh MP, Mullaney MJ, Tyler TF. Shoulder musculature activity and stabilization during upper extremity weight-bearing activities. $N$ Am J Sports Phys Ther. 2007;2(2):90-96. PubMed ID: 21522206

46. Vega Toro AS, Cools AM, de Oliveira AS. Instruction and feedback for conscious contraction of the abdominal muscles increases the scapular muscles activation during shoulder exercises. Man Ther. 2016;25:11-18. PubMed ID: 27422592 doi:10.1016/j.math.2016. 05.331

47. Kibler WB, Sciascia AD, Uhl TL, Tambay N, Cunningham T. Electromyographic analysis of specific exercises for scapular control in early phases of shoulder rehabilitation. Am J Sports Med. 2008;36(9):1789-1798. PubMed ID: 18469224 doi:10.1177/ 0363546508316281 
48. Reinold MM, Escamilla RF, Wilk KE. Current concepts in the scientific and clinical rationale behind exercises for glenohumeral and scapulothoracic musculature. J Orthop Sports Phys Ther. 2009; 39(2):105-117. PubMed ID: 19194023 doi:10.2519/jospt.2009. 2835

49. Timmons MK, Ericksen JJ, Yesilyaprak SS, Michener LA. Empty can exercise provokes more pain and has undesirable biomechanics compared with the full can exercise. J Shoulder Elbow Surg. 2016;25(4): 548-556. PubMed ID: 26577128 doi:10.1016/j.jse.2015.08.046

50. Thigpen CA, Padua DA, Michener LA, et al. Head and shoulder posture affect scapular mechanics and muscle activity in overhead tasks. J Electromyogr Kinesiol. 2010;20(4):701-709. PubMed ID: 20097090 doi:10.1016/j.jelekin.2009.12.003

51. Suprak DN, Bohannon J, Morales G, Stroschein J, San Juan JG. Scapular kinematics and shoulder elevation in a traditional push-up. J Athl Train. 2013;48(6):826-835. PubMed ID: 23952043 doi:10. 4085/1062-6050-48.5.08

52. Ekstrom RA, Bifulco KM, Lopau CJ, Andersen CF, Gough JR. Comparing the function of the upper and lower parts of the serratus anterior muscle using surface electromyography. J Orthop Sports Phys Ther. 2004;34(5):235-243. PubMed ID: 15189015 doi:10. 2519/jospt.2004.34.5.235 


\section{Appendix 1: Search Strategy}

\section{PubMed Search Strategy}

1. Trapezius (Text Word)

2. Serratus Anterior (Text Word)

3. 1 OR 2

4. Exercise Therapy (MeSH Terms)

5. Exercise (MeSH Terms)

6. Resistance Training (MeSH Terms)

7. Exercise (Text Word)

8. 4 OR 5 OR 6 OR 7

9. Electromyography (MeSH Terms)

10. Electromyography feedback (MeSH Terms)

11. Electromyography (Text Word)

12. EMG (Text Word)

13. Muscle activity (Text Word)

14. 9 OR 10 OR 11 OR 12 OR 13

15. $3 \& 8 \& 14$

Filters: Humans, English or Turkish

\section{EMBASE Search Strategy}

1. Trapezius (Text Word)

2. Trapezius muscle (Emtree)

3. Serratus Anterior (Text Word)

4. Serratus anterior muscle (Text Word)

5. 1 OR 2 OR 3 OR 4

6. Exercise (Emtree)

7. Exercise test (Emtree)

8. Exercise (Text Word)

9. Resistance training (Emtree)

10. 6 OR 7 OR 8 OR 9

11. Electromyography (Emtree)

12. Electromyogram (Emtree)

13. Electromyography (Text Word)

14. EMG (Text Word)

15. Muscle contraction (Emtree)

16. 11 OR 12 OR 13 OR 14 OR 15

17. $5 \& 10 \& 16$

Filters: Humans, English or Turkish
7. Exercise test

8. Exercise training

9. (exercise training or exercise program)

10. Resistance training

11. 5 OR 6 OR 7 OR 8 OR 910

12. Electromyography

13. Electromyogram

14. EMG

15. EMG activity

16. Muscle activity

17. Muscle contraction

18. Electromyography

19. 12 OR 13 OR 14 OR 15 OR 16 OR 17 OR 18

20. $4 \& 11 \& 19$

Filters: English or Turkish

\section{ULAKBIM Turkish Medical Database Search Strategy}

1. Trapez

2. Trapezius

3. Serratus anterior

4. 1 OR 2 OR 3

5. Egzersiz

6. Exercise

7. Direnç eğitimi

8. Resistance training

9. 5 OR 6 OR 7 OR 8

10. Electromyography

11. Elektromiyografi

12. EMG

13. Kas aktivitesi

14. Muscle activity

15. 10 OR 11 OR 12 OR 13 OR 14

16. $4 \& 9 \& 15$

\section{CINAHL Plus and SPORTDiscus With Full-Text} Search Strategy

1. Trapezius

2. Trapezius muscle

3. Serratus anterior

4. 1 OR 2 OR 3

5. Exercise

6. (Exercise or physical activity) 


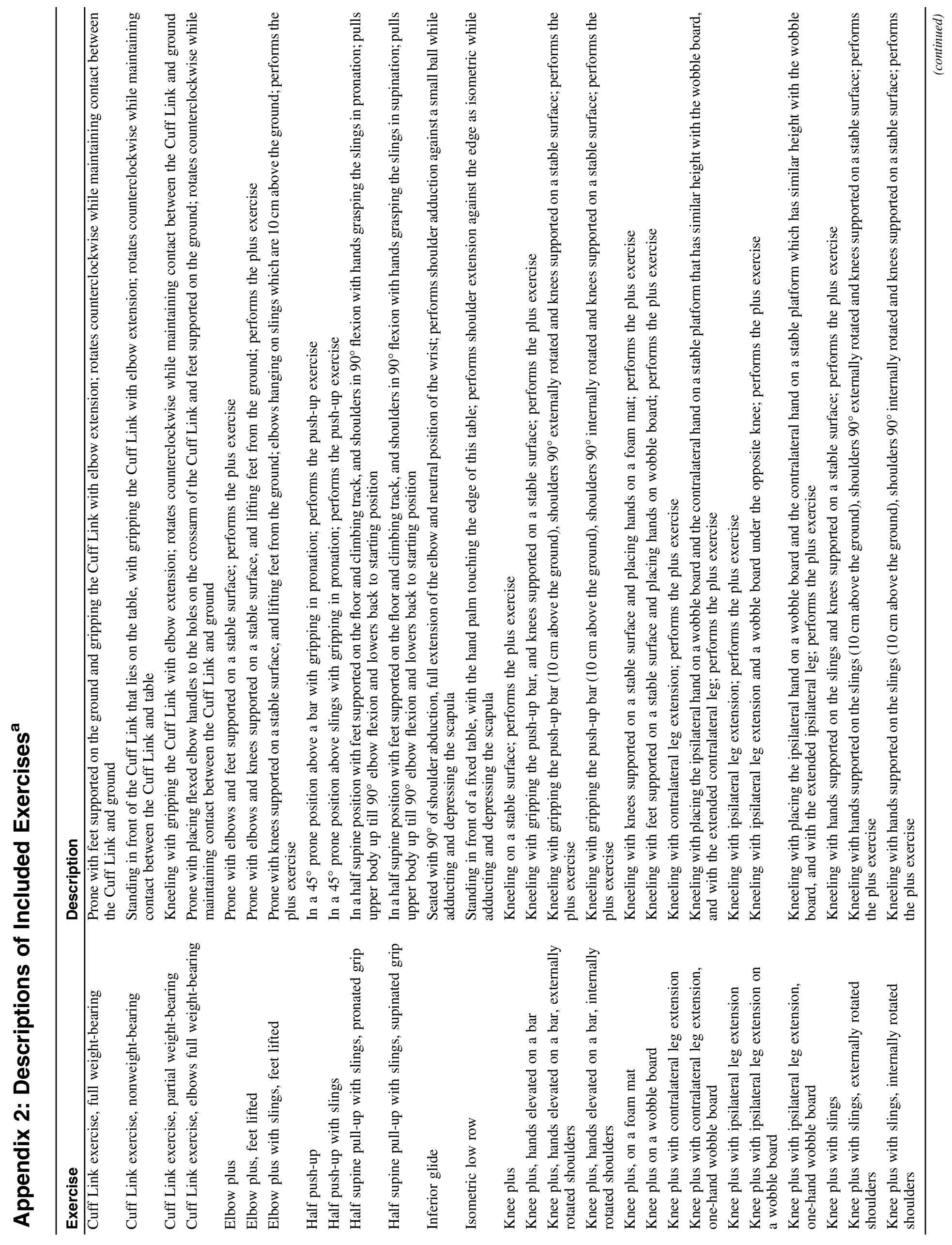




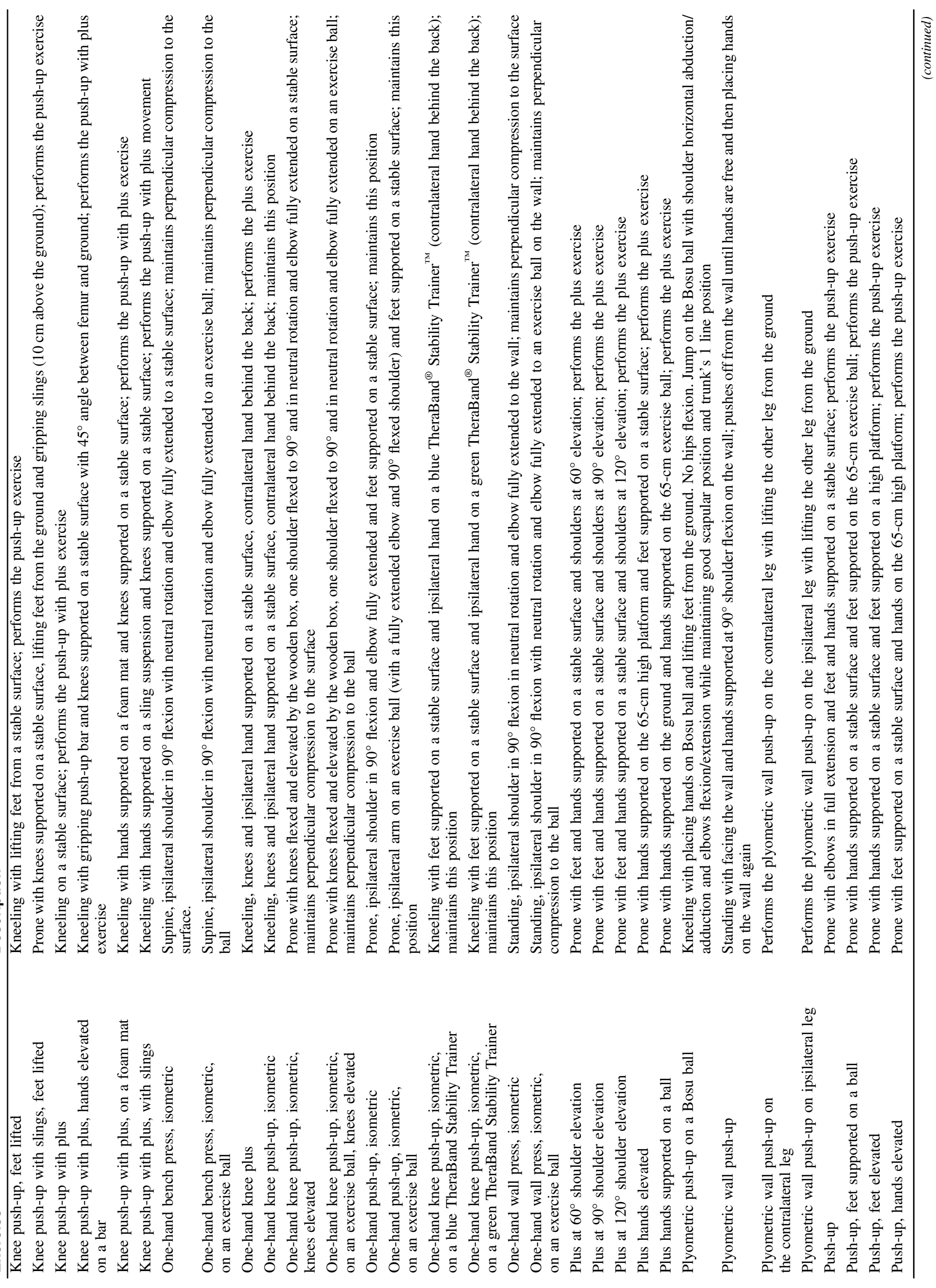




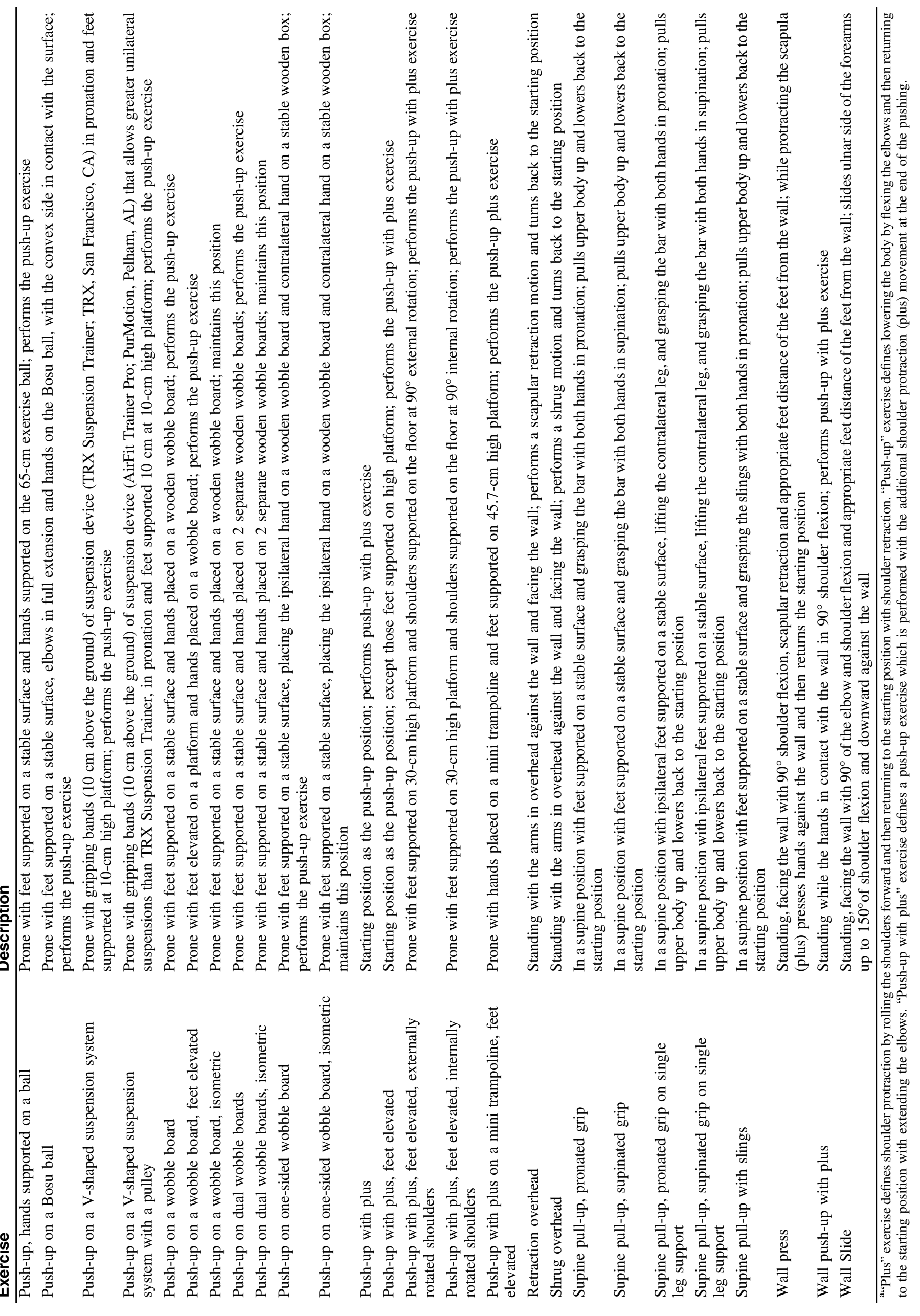

